\title{
SABERES E SABORES DAS GERAIS: uma proposta para o desenvolvimento do Food Design para cultura local
}

\author{
Nadja Maria Mourão \\ Universidade do Estado de Minas Gerais \\ nadjamourao@gmail.com \\ Rita de Castro Engler \\ Universidade do Estado de Minas Gerais \\ rcengler@uol.com.br \\ Fernanda Guimarães dos Santos \\ Universidade do Estado de Minas Gerais \\ fernandag39@hotmail.com
}

\begin{abstract}
Resumo: Este projeto utiliza a metodologia participativa do Programa "Comunidades Criativas das Geraes", com objetivo de beneficiar o cidadão e a produção artesanal, em comunidades de Minas Gerais. Nesta edição, o projeto investiga uma abordagem de Food Design, no município de Matozinhos, buscando resgatar a identidade cultural através da gastronomia local, seus processos e matéria prima, insumos utilizados. O foco principal são as possibilidades de incentivar a culinária local e seus produtos tradicionais. As atividades foram divididas em quatro etapas: pesquisa da região e dos alimentos, cadastro de participantes, estudo das receitas de quitutes e geração de propostas para comercialização. Foram realizadas oficinas que estimularam a educação do paladar, do conhecimento a respeito dos alimentos e das tradições alimentares locais. Em parceria com a comunidade o projeto desenvolveu novos produtos gastronômicos com ênfase nas características locais, com objetivo de atender ao turismo e aos eventos culturais. A região possui uma riqueza arqueológica e espeleológica de grutas pertencentes ao Ecomuseu do Carste Mocambeiro, polo atrativo para o turismo. Como resultado, incentivou-se o potencial para o desenvolvimento de quitutes e bolos, pelo resgate das receitas típicas regionais, disponibilidades de frutas da época e perfil turístico. Produzimos o catálogo "Saberes e sabores das Gerais" contendo receitas tradicionais e outras desenvolvidas pelo projeto, destinado a divulgar a riqueza e o potencial turístico da região.
\end{abstract}

Palavras-chave: Cultura, sabedoria popular, culinária tradicional, Food Design. 


\begin{abstract}
This project uses "Comunidades Criativas das Geraes" Program participatory methodology, in order to benefit citizens and artisan production in Minas Gerais communities. In this issue, the project investigates an approach to Food Design, in the municipality of Matozinhos, seeking to rescue the cultural identity through food, its processes and raw materials. The opportunities for promoting the culture of the local cuisine and its traditional products are highlighted. The activities were divided into four stages: research of the region and local cuisine, registration of participants, the study of recipes and generating proposals for marketing. Workshops that encouraged the education of taste, knowledge about food and local food traditions were held. In partnership with the community the project develops new gastronomic products with emphasis on local characteristics, aiming to attend tourism and cultural events demands. The region has a wealth of archaeological and speleological caves belonging to Ecomuseu Carste Mocambeiro, attractive hub for tourism. As a result, it encouraged the potential for the development of delicacies and cakes for the redemption of regional recipes, plenty of fruits and tourist profile. The book "Saberes e Sabores das Gerais" containing traditional recipes and others developed by the project was produced, to show region's touristic potenctial.
\end{abstract}

Keywords: Culture, folk lore, traditional cuisine, Food Design.

\title{
1 INTRODUÇÃO
}

Nas últimas décadas, observa-se que uma onda de alimentação fútil, apressada e padronizada tomou conta dos hábitos dos moradores urbanos, que pouco se importam com a qualidade e a importância dos alimentos que consomem. Através do design, é possível desenvolver métodos e recursos para enfrentar este modismo e resgatar as culinárias locais. Os produtos tradicionais podem ser resgatados pela educação do paladar, do conhecimento dos alimentos, do respeito à cultura e aos saberes dos antepassados, aplicando a praticidade e criatividade do design.

O movimento Slow Food defende a proteção dos alimentos tradicionais e sustentáveis de qualidade: dos ingredientes primários, a conservação de métodos de cultivo, do processamento e a defesa da biodiversidade, tanto de espécies cultivadas quanto das espécies silvestres.

Segundo a filosofia do Slow Food, "a única forma de agricultura que pode oferecer uma perspectiva de desenvolvimento é aquela baseada na sabedoria de comunidades locais em harmonia com os ecossistemas que as cercam" (IRVING; CERIANI, 2013). Destaca-se ainda, que o cultivo, a confecção e a comercialização de alimentos, estão associados de forma indissolúvel à economia, à política, à agricultura e ao meio ambiente.

Nas ultimas décadas, o design deixou de ser uma mera ferramenta para tornarse um modo de pensar e agir. Apresenta-se de forma transversal, interdisciplinar e sistêmica, cuja atuação está além do produto em si, gerando relação com o ambiente, conforme Heskett (2002). 
O design associado à organização sistemática de modos mais sustentáveis de se cultivar, produzir, comercializar e consumir alimentos de qualidade, fomenta 0 processo de melhoria da qualidade de vida das comunidades locais.

Em comunidades criativas busca-se ampliar os conhecimentos e inovações dos processos, em rede de trocas pelo mundo, onde possam ser criados ambientes de aprendizado e transformação dos indivíduos, e que a cultura sirva para o diálogo e como impulso criativo.

O conceito de Comunidades Criativas tem uma abordagem diferenciada, onde as relações lineares são evitadas dando forma preferencialmente a uma interação de cada membro de forma circular, tudo isso levando a redefinição entre os limites particulares e públicos, conforme Cipolla (2008) e Manzini (2005).

Este trabalho é parte dos resultados do projeto "Comunidades Criativas: uma proposta em Food Design" que tem como objetivo, investigar as possibilidades de incentivar a cultura da culinária local e seus produtos tradicionais, buscando resgatar a identidade cultural, através dos alimentos, seus processos e matéria prima. 0 desafio do projeto é contribuir para o resgate da culinária tradicional de Matozinhos e região, objeto de pesquisa.

A metodologia utilizada em Comunidades Criativas utiliza-se da "percepção do potencial das iniciativas espontâneas de grupos que desenvolvem trabalhos cooperativos de forma inovadora para resolver problemas em seu dia a dia" (MANZINI, 2008, p. 09).

O projeto foi dividido em quatro etapas: pesquisa e registro dos aspectos gerais do território e da culinária na região, cadastro de participantes, estudo das receitas locais e geração de propostas para comercialização. A proposta procura soluções em Food Design, que tornam os alimentos atrativos, nutricionais e de fácil preparo, utilizando os frutos coletados pela comunidade.

Os sabores, aromas e costumes típicos de um lugar podem ser atrativos para turistas que desejam contato com a cultura local. "Não é somente o ato de provar os pratos que atrai os visitantes, mas também o fato de poder conhecer ritos e hábitos associados à gastronomia de um povo e a possibilidade de visitar museus e outras atrações com essa temática." (OLIVEIRA, 2007, p. 263).

$\mathrm{Na}$ etapa de pesquisa e registros buscou-se conhecer o objeto da pesquisa, ou seja, a cidade de Matozinhos, no contexto histórico, social, cultural e ambiental. Através dos dados levantados foi possível elaborar, com a participação dos membros da comunidade, uma proposta de atuação adequada.

\section{A CIDADE DE MATOZINHOS}

O município de Matozinhos, em Minas Gerais, foi selecionado como objeto de pesquisa. Conforme Granbel (2011a) possui clima tropical, com extensão territorial de $253,11 \mathrm{Km}^{2}$ (IBGE), pertence à região metropolitana de Belo Horizonte, distante por 51 km da capital. Faz limites com os municípios Pedro Leopoldo, Prudente de Morais, Capim Branco, Esmeraldas, Baldin, Jaboticatubas e Funilância. Possui 32.973 habitantes (Censo 2010) e IDH (índice de desenvolvimento Humano) de 0,774 (IBGE, 2000).

Matozinhos nasceu em torno da Igreja Senhor Bom Jesus do Matozinhos, padroeiro do lugar, logo após sua imagem ter sido encontrada nas ruínas do acampamento da bandeira de Dom Rodrigo de Castelo Branco. Da fundação da cidade 
no século XVIII, preserva algumas igrejinhas e a sede da estação da Estrada de Ferro Central do Brasil, no estilo colonial mineiro. A Fazenda Jaguará, fundada em 1724, é um dos mais importantes estabelecimentos rurais do período. Na propriedade existe um belo casarão, com casa de agregados, dependências de marcenaria, carpintaria, engenho, moinho d água e galpões. No lugar há ainda as ruínas da Igreja de Nossa Senhora da Conceição da Jaguará, uma das poucas obras totalmente atribuídas ao mestre Aleijadinho, da qual apenas a fachada ainda resiste às intempéries. Ainda nas terras da fazenda, em meio à densa vegetação do alto da colina, vê-se um castelo construído no início do século passado pelo inglês George Chalmers. Dentro do território montanhoso de Matozinhos, está o Pico da Roseira, com 1.011 metros de altitude, o ponto mais elevado da região, onde se encontra também a nascente do Ribeirão da Mata, conforme Granbel (2011b).

A formação de rocha calcária, atualmente pertencente ao Ecomuseu do Carste Mocambeiro, revela a grande riqueza arqueológica e espeleológica da região, onde se destacam as grutas "Poções", "Cerca Grande" e "Ballet". Nesta última, conforme site Portal do Turismo, há um painel de pintura rupestre, com ilustrações de vivências de homens e mulheres que habitavam a região na Pré-História.

O Ecomuseu do Carste Mocambeiro é um parque natural localizado na região cárstica de Lagoa Santa, a $46 \mathrm{~km}$ de Belo Horizonte. Conforme site Ecomuseu do Mocambeiro é um rico patrimônio natural e cultural, com elementos naturais conhecidos mundialmente a partir de Peter W. Lund, em fins de século XIX. É um museu a céu aberto que tem como acervo formações cársticas, lagoas, estruturas arquitetônicas rurais de interesse histórico local e mundial.

A população local é alegre, com espírito festivo. Convive com diversos problemas de uma cidade de pequeno porte e poucos recursos, porém observa-se que existe um grande interesse na produção de alimentos. Nas entrevistas percebeu-se que os festejos e a religiosidade justificam os investimentos em pequenos negócios de produção de comercialização de produtos de milho, queijos e frutas da região.

\section{CULTURA, RELIGIÃO E FESTA}

O "Jubileu do Senhor Bom Jesus do Matozinhos" é a maior festa da cidade e é realizada desde o ano de 1787, no período de 07 a 16 de setembro. Nessa época, a cidade se transforma com a vinda de milhares de romeiros e com intensa movimentação de fiéis e de comerciantes que se instalam na colina do Santuário durante a festa, para agradecer ou implorar graças ao Bom Jesus (GOULART; TABULEIRO, 2007).

A festa, embora tenha também conotação social e comercial decorrente do fluxo de romeiros e visitantes, conserva seu caráter religioso. São realizadas missas e exposição do Santíssimo Sacramento durante todos os dias do evento, sendo que no último dia, a imagem santa é levada em procissão pelas ruas da cidade. O Jubileu do Senhor Bom Jesus acontece todos os anos. A tradição do evento atrai muitos fieis como foi registrado pelo acervo historio de Celso Cirino, conforme figura 1.

Durante os dias de evento, são armadas "barraquinhas" nas ruas para atender aos visitantes e romeiros. Comercializar alimentos e produtos artesanais durante 0 Jubileu é um costume cultural, que iniciou nas quermesses da igreja matriz. Atualmente, são diversas barraquinhas que ocupam o perímetro central do município, 
durante os festejos. São apreciados os queijos e outros derivados como o requeijão e doces populares como, doce de leite, cubu de milho, broas, bolos e outros quitutes.

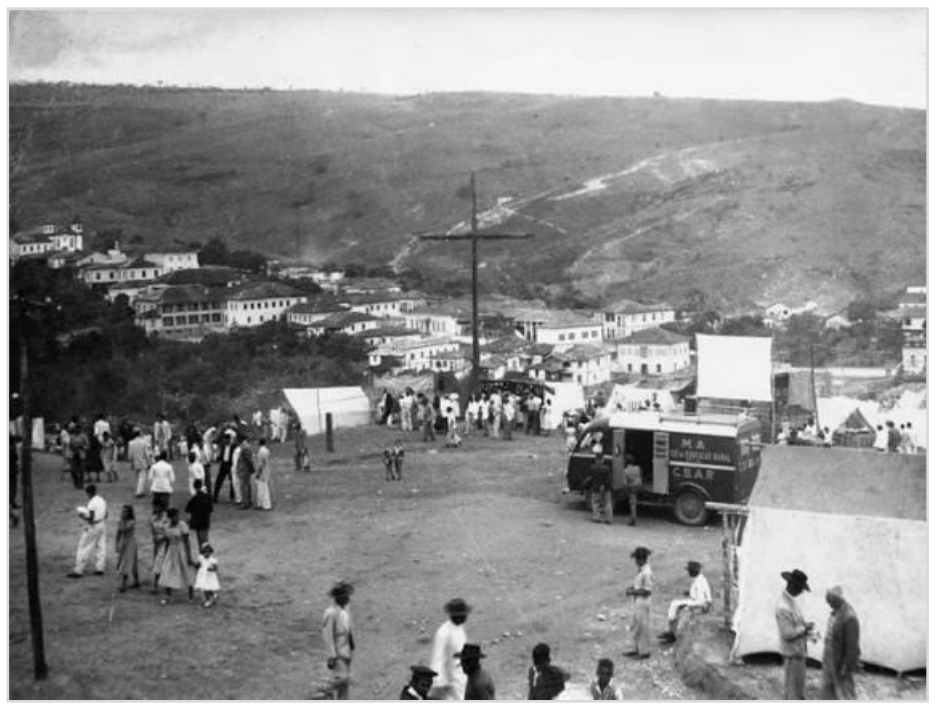

Figuras 1 - Acervo histórico de Celso Cirino.

Fonte: Disponível na internet por http em: <www.santuariodobomjesus.org.br>. Acesso em 20 abr. 2014.

\section{IDENTIFICAÇÃO DOS PRODUTOS E CULINÁRIA LOCAL}

A etapa do mapeamento teve como objetivo conhecer a região, entrevistar os moradores, identificar os frutos e planejar os encontros e as oficinas, em parceria com a comunidade local. A pesquisa registrou que são os poucos produtos típicos da região em uso, devido às dificuldades de produção e pouca criatividade para reaproveitá-los.

A região possui pequenas plantações, geralmente da agricultura familiar, de jiló, alho, urucum, cravo, verduras como almeirão, couve, alface. Nos pomares e nos terrenos das residências são encontradas algumas árvores frutíferas em produção de: acerola, abacate, banana, goiaba, jabuticaba, laranja, limão cravo, manga e mexerica. Além destes frutos, depara-se com o plantio de cana-de-açúcar e milho. No entanto, durante o período da pesquisa foi observado um grande numero de abacateiros e limoeiros carregados de frutos, nas andanças pelos bairros e arredores do município.

\subsection{Algumas frutas da região}

Em Minas Gerais existe uma grande variedade de frutas que são facilmente encontradas principalmente no interior do estado, algumas nativas e outras exóticas que se adaptaram ao território. Dentre elas, as que mais chamaram atenção em abundância na região de Matozinhos durante o período da pesquisa, foram o abacate e o limão cravo.

O Abacate, fruto do abacateiro, cientificamente conhecido como Persea americana, da família das Laureáceas, é bastante nutritivo, pois contém abundante quantidade de gorduras vegetais. Ele é indicado para casos de fraqueza e desnutrição, bem como na erradicação de dores e prisão de ventre. As folhas frescas do abacateiro, quando mascadas, restabelecem a saúde da boca, fortalecendo gengivas e dentes, e combate enjoos. Originário da América Latina, o abacate é muito popular no Brasil. Suas propriedades the permitem inclusive melhorar as condições arteriais, diminuir o mau colesterol e expandir os vasos sanguíneos, bem como impedir a veiculação de trinta agentes produtores do câncer, conforme Lorenzzi (2006). 
Gastronomicamente ele é igualmente flexível, muito utilizado na confecção de saladas criativas, como o exótico Guacomole Mexicano, em sorvetes, deliciosas sobremesas, entre outros pratos. Lorenzzi (2006) relata que o abacate possui uma polpa verde-amarelada, de textura mole, posicionada em torno de uma ampla semente; ela é justamente a porção comestível da fruta. Na forma natural, é passível de ser preservado na geladeira de 2 a 4 semanas. Seu melhor período de produção vai de fevereiro a agosto.

O Limão Cravo originário da China, pertence à família das Rutáceas. As plantas de limão Cravo são muito vigorosas e produzem grande quantidade de frutos com muitas sementes por fruto. O limão Cravo adaptou-se muito bem ao clima e ao solo brasileiros e hoje e encontrado na maior parte do país como uma planta selvagem, nas montanhas, pastos ou beiras de rios, conforme Lorenzzi (2006). Cientistas começam a estudar o óleo essencial extraído da casca deste limão, que até o momento, apresenta propriedades terapêuticas acima da media, quando comparado às outras variedades.

Trata-se de uma variedade bem rústica, motivo pelo qual é conhecido por vários nomes regionais: limão rosa, limão capeta, limão vinagre, entre outros. Tem sabor e aroma bem característicos, abundante em sementes e suco ácido, por ser a variedade com menor teor de frutose, descreve Lorenzzi (2006). Possui propriedades sedativas, antiespasmódicas, sudorífias, vermífugas, antiescorbúticas, alcalinizante, depurativo e tônico digestiva. É indicado no combate dores reumático, diarreias, astenia, dispepsia, escorbuto, hipertensão arterial, aterosclerose, afecções das vias biliares. Para uso externo é antisséptico.

\subsection{Culinária local}

A pesquisa registrou alguns alimentos e métodos de execução, dos participantes do projeto, na cidade de Matozinhos. Foi realizado um seminário de sensibilização, apresentando o projeto e a ideia de utilizar frutos da região para geração de renda. O seminário contou com a participação de moradores locais, cadastrados para participação das oficinas de culinária.

Durante as atividades, os participantes apresentaram seus produtos, que são comercializados em baixa produção. Houve degustação de doces de leite, de limão, mamão e queijos diversos. Foram confeccionados quitutes como biscoitos fritos e assados de polvilho, pão de queijo, cubu de milho, broas e bolos.

Durante o seminário foi proposto à realização de oficinas de culinária com o objetivo de experimentar novas técnicas e receitas. Foram realizadas oficinas que estimularam a educação do paladar, do conhecimento a respeito dos alimentos e das tradições alimentares locais. As oficinas ocorreram no distrito de Mocambeiro e no Centro Cultural de Matozinhos, com a participação efetiva dos participantes cadastrados.

\section{ANÁLISE DAS OFICINAS DOS SABERES E SABORES LOCAIS}

As "oficinas dos saberes e sabores" possibilitaram o resgate dos produtos da culinária local. Em cada atividade os participantes retalavam como aprenderam a cozinhar, como eram tratados os alimentos e em quais momentos os produtos eram preparados. Das receitas mais populares na região destacam-se os produtos derivados do milho. 
Na região do presente estudo, predomina a paisagem cárstica, a produção do milho ocorre pela agricultura familiar, facilitando o contato com o alimento, destinada ao consumo próprio e à pecuária leiteira. Assim, no diálogo entre os participantes, registra-se a importância do milho e do leite, na elaboração dos alimentos. Foram contadas estórias de antepassados que trabalhavam nas lavouras, em sítios e fazendas da região. Os eventos de destaque em Matozinhos são as festas religiosas e eventos culturais como: Folia de Reis, Carnaval, Congado, Boi da Manta, Semana Santa, Jubileu do Senhor Bom Jesus, Festa de Nossa Senhora do Rosário, Festas Juninas, entre outros.

"As festas eram mais frequentes e a população participava dos preparativos", relata uma das moradoras. "O Jubileu de Bom Jesus de Matozinhos atrai muitos turistas e fieis. Mas, a culinária não é o destaque principal, pois as barracas vendem de tudo", declara outra participante. As festas juninas foram as mais comentadas como evento para a culinária. Além das danças e festejos em vários lugares do município, geram oportunidade de renda, no preparo de bolos de milho, broas, pipocas, pamonhas e o popular cubu de milho - predileto da comunidade local. O cubu é preparado como um bolo de milho, assado enrolado em folhas de bananeira.

Algumas receitas foram discutidas pelo grupo. Alguns mais tradicionais e outros mais práticos, mas todos possuem uma receita de família. Ao relatarem as receitas, perceberam que, devido às facilidades de consumo de produtos semiprontos, muitas receitas da culinária local não são mais praticadas há muitos anos. Foi colocado o desafio para cada participante de encontrar uma receita de culinária local e experimentá-la.

Para aplicar o Food Design, deve-se levar em conta a plasticidade, a sustentabilidade e a estética do produto. Assim, os doces em calda e compotas, como o Doce de limão em calda, podem ser comercializados em potes de vidro, decorados com fitas e tecidos de chita. O estudo considera que as características das festas locais são atrativas que merecem atenção. É importante lembrar que as etiquetas de ingredientes, nutrientes e prazo de validade do produto são necessárias, para que possam ser registrados e comercializados.

\section{GERAÇÃO DE PRODUTOS DO PROJETO}

Os participantes das oficinas retalavam como aprenderam a cozinhar, como eram tratados os alimentos e em quais momentos cada produto era elaborado. Das receitas mais populares na região destacam-se os produtos derivados do milho. $\mathrm{Na}$ região do presente estudo, predomina a paisagem cárstica, a produção do milho é ocorre pela agricultura familiar, facilitando o contato com o alimento, destinada ao consumo próprio e à pecuária leiteira. O costume das comunidades rurais de tomar um cafezinho e fazer um lanchinho, com bolo de fubá, biscoito e pão de queijo, é uma das características do grupo de amostragem.

Este hábito, agregado a proposta para geração de novas receitas da culinária local, torna-se uma ferramenta de trabalho participativo, pela fomentação de diálogo aberto e o prazer de saborear os quitutes elaborados pelo grupo focal.

A população local é bastante criativa, mas, carece de estímulos para suas produções em culinária. Os habitantes, em sua maioria, vivem centrados nos acontecimentos locais e muitos nunca saíram da cidade. Porém, possuem interesse investir no seu próprio negócio e em estimular o do turismo local, gerando a opção de turismo gastronômico. 
A equipe se empenhou na elaboração de uma linha de bolos, para produção em formas quadradas ou redondas com furo, costume local, ou em forminhas individuais, para comercialização.

Com a participação de uma nutricionista da região, foram selecionados os ingredientes mais populares, de baixo custo e que poderiam ser utilizados com versatilidade: o fubá de milho, o açúcar, margarina ou óleo, leite ou coalhada e ovos. Além destes, acrescentam-se os ingredientes locais identificados para o desenvolvimento de novas receitas: caldo de cana, abacate e limão.

Outro fator importante é a relação dos produtos desenvolvidos com a cultura local. Assim, buscou nas bases do Food Design, vincular os ingredientes, o formato, a estética e as possibilidades de uso de embalagens, para estimular a comercialização.

Para cada estudo de bolo ou broa, foram elaborados esquemas de ingredientes e seus sabores (cores e consistências), estudo de um patrimônio cultural ou festejo, processo de produção, apresentação e comercialização.

A figura 2 apresenta um exemplo de estudo da identidade do patrimônio cultural com o produto (bolo) denominado Garapa das Grutas, em homenagem ao conjunto de grutas da região:
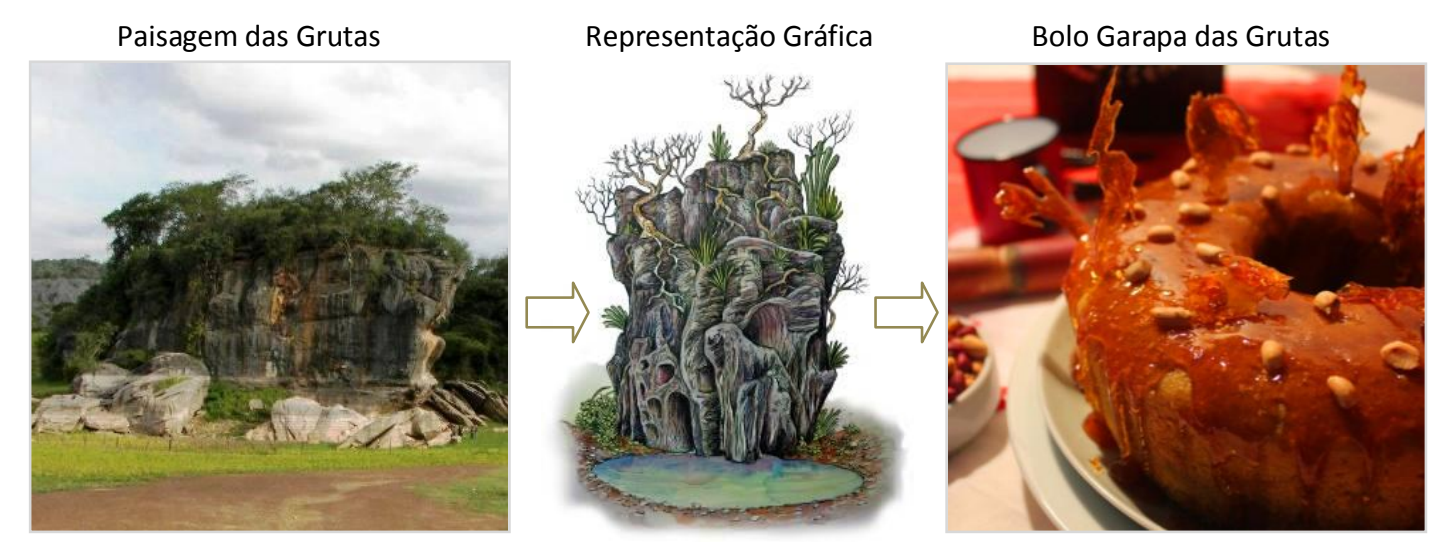

Figura 2 - Estudo de imagens no desenvolvimento de produtos Fonte: Arquivo CEDTec, com base na pesquisa realizada, 2014.

Entre os produtos desenvolvidos, destacam-se cinco receitas de bolos, aprovados pela comunidade e que poderão ser utilizados para comercialização:

- "BOlO garapa das grutas"

O Bolo "Garapa das Grutas" é elaborado com fubá, trigo e caldo de cana. Acrescenta-se amendoim torrado e amassado à massa pronta para assar, alguns cravos e uma colher de cachaça. O bolo adquire um aspecto rústico, como as paredes das grutas. O sabor deste bolo poderá ser associado ao importante ciclo das grutas do Carste. Sugere-se a forma redonda com furos, ou forminhas individuais, adicionando alguns amendoins na decoração de cobertura, revestido com papel celofane transparente.

- "BOLO MOCAMBEIRO"

O Bolo Mocambeiro tem como principais ingredientes o abacate e a farinha de trigo. Na receita, foi acrescento o suco de limão e folhas de hortelã, que acentuam o 
sabor do abacate. A cobertura é de suco de limão e açúcar confeiteiro, que dá um aspecto esverdeado, considerando que a região de Mocambeiro possui o Parque Estadual Cerca Grande localizado em Mocambeiro. Na estética do bolo, sugere-se cortá-lo em pedaços cúbicos, para comercialização em caixas, com a imagem do local estampada na parte superior da embalagem.

\section{- "BROA SUMIDOURO"}

A Broa de fubá com leite azedo é à base desta receita. Porém, são acrescentados pedaços de chocolate meio amargo, antes de a massa ir ao forno. Algumas gotas de baunilha enriquecem o sabor da broa. Depois de assada, acrescentase uma calda de chocolate deixando que escorra pelas laterais. O nome é uma homenagem ao sumidouro de Cerca Grande. A embalagem deste bolo deve favorecer a cobertura, como caixas mais largas que o bolo, revestida de papel celofane.

\section{- "BOLO JAGUARA"}

A receita base deste bolo e o suco de limão como farinha de trigo e ovos. Um pouco de raspas de limão e coco ralado, são incluídas na massa pronta para assar. Na sequencia, acrescente a calda de laranja que somada ao limão e ao coco. O nome do bolo é uma homenagem ao Patrimônio histórico cultural da Fazenda Jaguara. Poderá ser comercializado em qualquer embalagem, inclusive cortado em pedaços e revestido em papel celofane, amarrado com fitas de cetim.

\section{- "BOLO JUBILEU DE MATOZINHOS"}

O Bolo de fubá com iogurte é massa base, que foi modificada com adição de pedaços de queijo Minas e goiabada cascão, que adquiri um sabor especial, para a festa do Jubileu de Bom Jesus de Matozinhos, que ocorre no mês de setembro, no município. O colorido dos ingredientes é um elemento diferenciador deste bolo. Para a cobertura, sugere-se calda de açúcar de confeiteiro e pedaços de goiabada e queijo, conforme figura 3.

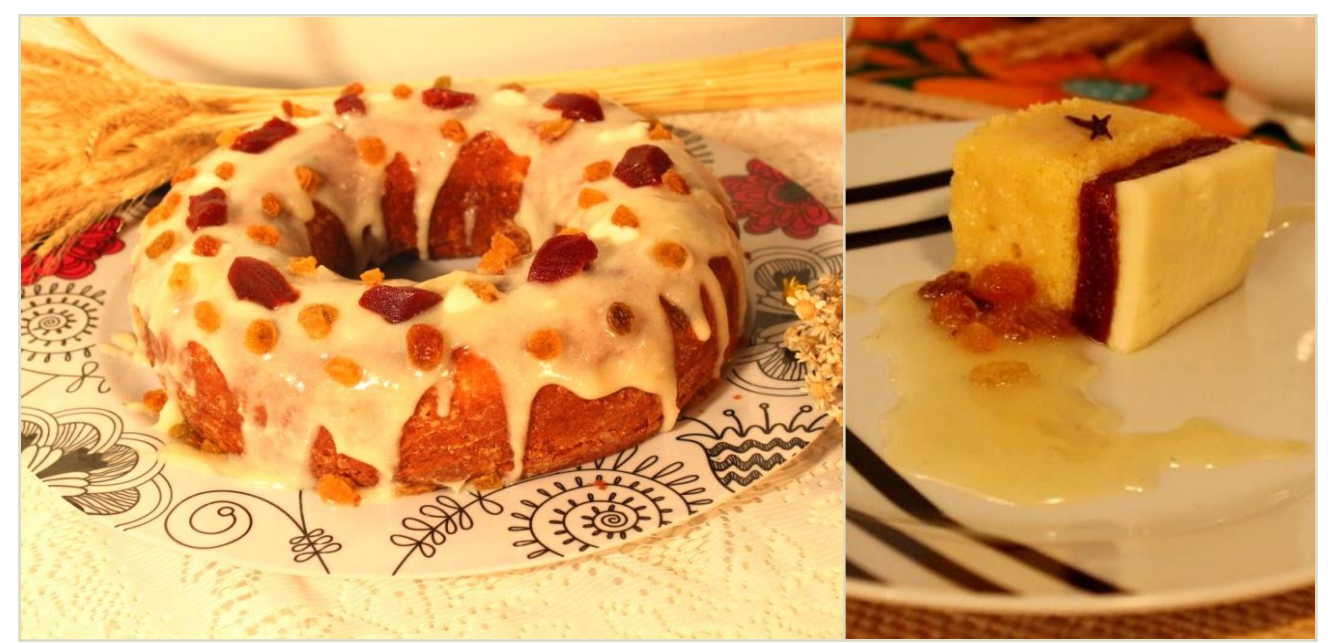

Figura 3 - Imagens do bolo Jubileu de Matozinhos e fatia para comercialização. Fonte: Arquivo CEDTec, com base na pesquisa realizada, 2014. 


\section{CONCLUSÃO}

O "Projeto Comunidades Criativas das Gerais; uma abordagem de Food Design" teve como objetivo resgatar os sabores tradicionais e memória gustativa, utilizando os produtos típicos de Minas Gerais e criando novas aplicações, em Matozinhos - MG.

Foi observado que os moradores do de Matozinhos e do Distrito de Mocambeiro têm interesse em adquirir novas técnicas e receitas gastronômicas, para usarem nas suas produções. Durante a realização do projeto, foi percebido que, na medida em que as atividades eram executadas (seminários e as oficinas), o número de participantes aumentava a cada evento.

A população local percebe a necessidade de investimento para estimular o turismo e a gastronomia aparece como uma opção viável, capaz de atrair novos turistas e gerar renda para a população. Uma vez estimulados pelo projeto, mostraram-se participativos e criativos, envolvendo-se ativamente no processo de criação/experimentação de novas técnicas e receitas.

O projeto buscou realizar receitas sustentáveis, em que a comunidade poderá produzir produtos gastronômicos com identidade local, valorizando os produtos nativos, com um custo mais baixo e mais atrativo para os turistas ávidos por novidades e curiosidades, como os visitantes do Ecomuseu.

O potencial para o desenvolvimento da gastronomia é expressivo, devido à riqueza de frutos e frutas regionais, e da possibilidade do resgate das receitas típicas, pouco difundidas fora da região.

\section{REFERÊNCIAS}

CIPOLLA, Carla. Creative communities as 'relational' innovations: a service design approach. In: Jegou, F., Manzini, E.Collaborative Services. Social Innovation and Design for Sustainability. Milan: POLI.design, 2008.

ECOMUSEUMOCAMBEIRO. Disponível na internet por http em: <http://ecomuseumocambeiro.blogspot.com.br/>. Acesso em 20 abr. 2014.

FERIAS.TUR.BR. Mocambeiro. Disponível na internet por http em: <http://www.ferias.tur.br/informacoes/3427/mocambeiro-mg.html\#ixzz2rBRb7rM6>. Acesso em: 23 Jan. 2014.

GOULART, Ézio Dornela; TABULEIRO, Sociedade dos Amigos do. Plano de Desenvolvimento Sustentável Município de Conceição do Mato Dentro (2007). Disponível em hptt: <http://cmd.mg.gov.br/manifestacoes-culturais-ereligiosas/jubileu-do-senhor-bom-jesus-do-matozinhos>. Acesso em 20 abr. 2014.

GOVERNO DE MINAS GERAIS. Disponível na internet por http em: <http://www.mg.gov.br/governomg/ecp/contents.do?evento=conteudo\&idConteudo

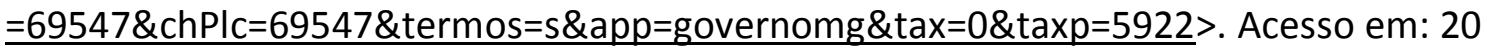
jan. 2014. 
GRANBEL. História de Matozinhos. Postado em 01 fev. 2011. Disponível na internet por http em: <http://www.ferias.tur.br/informacoes/3401/matozinhosmg.html\#ixzz2v6e31U00>. Acesso em 20 abr. 2014.(a)

GRANBEL. Informações Sócio-Econômicas de Matozinhos/MG. Postado em 03 fev. 2011. Disponível na internet por http em: $<$ http://granbel.com.br/index.php/municipios-metropolitanos/102-municipio-dematozinhos-municipio-de-matozinhos/216-informacoes-socio-economicas-dematozinhosmg.html>. Acesso em 20 abr. 2014. (b)

HESKETT, John. Values and value in design. Unpublished manuscript, Illinois Institute of Technology, Chicago, 2002.

IRVING, John; CERIANI, Silvia. Manual Slow Food. Edição 2013. Disponível na internet por http em: <http://www.slowfoodbrasil.com/documentos/manual-do-slowfood2013.pdf> Acesso em 20 abr. 2014.

LORENZI, Harri et al. Frutas Brasileiras e Exóticas Cultivadas (de consumo in natura). Instituto Plantarum. 2006.

MANZINI, Ezio. Enabling solutions for creative communities. Social innovation and design for sustainability. Design matters, n. 10, 2005.

Design para a inovação social e sustentabilidade: Comunidades Criativas organizações colaborativas e novas redes projetivas. Rio de Janeiro: E-papers, 2008.

PORTAL DO TURISMO. Disponível em hptt por: $<$ http://www.minasgerais.com.br/destinos/matozinhos/\#sthash.JYrQ9h9p.dpuf $>$.

Acesso em 20 abr. 2014.

OLIVEIRA, Simão. La importancia de la gastronomía en el turismo: Un ejemplo de Mealhada - Portugal Estudios y perspectivas en turismo, 2007. Disponível em: <http://www.scielo.org.ar/scielo.php?script=sci_arttext\&pid=S1851-

$17322007000300001 \&$ Ing=es\&nrm=iso>. Acesso em 02 mai. 2014.

SANTUÁRIO DO BOM JESUS. Disponível na internet por http em: <www.santuariodobomjesus.org.br>. Acesso em 20 abr. 2014.

WHOLE FOODS MARKET. Disponível na internet por http em: <www.wholefoodsmarket.com>. Acesso em 20 dez. 2013.

\section{AGRADECIMENTOS}

FAPEMIG - Fundação de Amparo à Pesquisa de Minas Gerais

CEDTec - Centro de Estudos em Design \& Tecnologia

Prefeitura de Matozinhos/MG

ADAO - Associação Desenvolvimento Artes e Ofícios 